\title{
El concepto de trabajo vivo desde el marxismo latinoamericano. Notas a partir de la obra de Enrique Dussel y Álvaro García Linera
}

The concept of living work from Latin American Marxism. Notes from the work of Enrique Dussel and Álvaro García Linera

\author{
J. Fabián Cabaluz D.* \\ Tomás Torres López**
}

\begin{abstract}
Resumen: El presente artículo trata sobre el concepto de trabajo vivo en dos autores referenciales del marxismo latinoamericano, tales como el filósofo argentino-mexicano Enrique Dussel y el sociólogo y vicepresidente boliviano Álvaro García Linera. A partir de una metodología cualitativa, de carácter hermenéutico, implementando el método de análisis de contenidos, el artículo profundiza, en un primer momento, en el concepto de trabajo vivo desarrollado por ambos autores, para avanzar en un segundo momento, en un ejercicio interpretativo que lo vincula con los conceptos de comunidad y movimientos sociales, bosquejando de esta manera, potencialidades teóricas para el desarrollo de una dimensión no economicista del concepto.
\end{abstract}

Palabras claves: Enrirque Dussel, Álvaro García Linera, Trabajo vivo, marxismo latinoamericano.

\begin{abstract}
This article deals with the concept of living work in two authors who interpret Latin American Marxism. The philosopher Enrique Dussel, on the one hand, and the sociologist and vice-president Álvaro García Linera, on the other. With a hermeneutic methodology, using the content analysis, we deepen, in the first moment, on the concept of living work developed by this two intellectuals for, in a second moment, advance in a interpretative exercise that links this with notions of community and social movement, sketching, in this way, the theoretical potentialities for the development of one dimension non economic of the living work.
\end{abstract}

Key words: Enrique Dussel, Álvaro García Linera, living work, latinamerican marxism.

Recibido: 15 mayo 2019 Aceptado: 10 agosto 2019

\footnotetext{
* Docente e investigador de la Escuela de Pedagogía en Historia y Ciencias Sociales de la Universidad Academia de Humanismo Cristiano. Doctor (C) en Estudios Latinoamericanos, Universidad de Chile. Becario CONICYT, Doctorado Nacional, 2016, folio N²1160786. fabiancabaluz@gmail.com

** Sociólogo, estudiante de Doctorado en Sociología de la Universidad Alberto Hurtado, académico de la Escuela de Sociología de la Universidad Católica Silva Henríquez, becario CONICYT, Doctorado Nacional 2019, folio No: 21190039. tom.torres.lopez@gmail.com
} 


\section{Enrique Dussel y Álvaro García Linera: Referentes del marxismo latinoamericano}

Tres grandes problemas emergen al momento de referirnos al marxismo latinoamericano. El primero de ellos, consiste en la existencia de un vacío y/o silencio en las grandes obras que han analizado la historicidad del marxismo1, puesto que si bien han visibilizado vertientes, corrientes y tradiciones, relevando diferencias y polémicas internas, han omitido referencias al desarrollo del marxismo latinoamericano. De la mano de lo anterior, existe un segundo problema, asociado a la insuficiencia de investigaciones en torno al marxismo latinoamericano, las que han estado particularmente centradas en la obra del peruano José Carlos Mariátegui, lo que se reduce a determinados sectores del continente americano, existiendo enormes lagunas en lo que respecta a otras zonas socio-económicas y culturales de América Latina. Y un tercer problema nos remite a la multiplicidad de planos (discursivo, organizaciones políticas, militancias, intelectuales, etc.) y disciplinas (sociología, filosofía, historia, etc.) en que se ha desarrollado el marxismo latinoamericano, todo lo cual dificulta la realización de investigaciones centradas en el plano de la historia de las ideas o de la cultura e instala el desafío de realizar indagaciones integrales, lo que sin lugar a dudas, dota de complejidad el trabajo investigativo².

Considerando las problemáticas señaladas, el presente artículo pretende analizar un pequeño capítulo de la producción teórica del marxismo latinoamericano, particularmente el abordaje realizado en torno al concepto de trabajo vivo. Para ello, nos detendremos en analizarlo, a partir de la producción teórico-política de dos incuestionables referentes intelectuales del marxismo latinoamericano, a saber, el filósofo argentino-mexicano Enrique Dussel y el político boliviano Álvaro García Linera. A partir de una metodología cualitativa, de carácter hermenéutico, implementando el método de análisis de contenidos, el artículo se detiene inicialmente en los principales nudos que constituyen el concepto de trabajo vivo en los autores, para posteriormente, establecer un ejercicio interpretativo que lo vincula con los conceptos de comunidad y movimientos sociales. Finalmente, el artículo proyecta potencialidades teóricas asociadas al eje conceptual: trabajo vivo - comunidad movimientos sociales.

Desde nuestra perspectiva, Enrique Dussel y Álvaro García Linera, son referentes actuales del marxismo latinoamericano, al menos por dos elementos: en primer lugar, porque han logrado desarrollar pensamiento creativo y original, preocupándose por no reproducir de manera abstracta los planteamientos de Karl Marx y los/as marxistas, desplegando un

\footnotetext{
1 Hobsbawm, Eric, Historia del marxismo. El marxismo en tiempos de Marx, España, Brugera Vol. 2, 1980a; Hobsbawm, Eric, Historia del marxismo. El marxismo en la época de la II Internacional, España, Brugera Vol. 3, 1980b; Hobsbawm, Eric, Historia del marxismo. El marxismo en la época de la II Internacional, España, Brugera vol. 4, 1980c; Hobsbawm, Eric, Historia del marxismo. El marxismo en la época de la II Internacional, España, Brugera vol. 5, 1981; Kolakowski, Leszek, Las principales corrientes del marxismo. Tomo II: La edad de oro. Alianza Editorial, Madrid, 1985.

2 Acha, Omar \& D'Antonio, Débora "Cartografía y perspectivas del marxismo latinoamericano", Revista Contra Corriente, México, 2010, pp. 210-256.
} 
arsenal teórico y conceptual que pretende ser coherente con la realidad específica y concreta de la región. Es decir, son intelectuales que han avanzado en elaborar teoría situada y contextualizada, lo que genera tensiones y rupturas con las aún vigentes concepciones del marxismo ortodoxo y eurocéntrico. Y en segundo lugar, y vinculado a lo anterior, porque los autores han avanzado en un ejercicio teórico y político de traducción ubicada geopolíticamente, es decir, han intentado traducir la crítica universal al capitalismo, a partir de las relaciones sociales de dominación y explotación capitalistas considerando los dilemas específicos que se presentan en América Latina. En este proceso de traducción, se ha producido un proceso signado por mediaciones, intercambios y contaminaciones. En otros términos, podemos sostener que en sus obras encontramos un pensamiento poroso que entrecruza ideologías de raigambre emancipatoria, con intentos de explicar condiciones históricas específicas de Latinoamérica. En esta clave, proponemos analizar el concepto de trabajo vivo y sus vinculaciones con los conceptos de comunidad y movimientos sociales ${ }^{3}$.

\section{Trabajo vivo en la filosofía de la liberación de Enrique Dussel}

\section{Filosofía de la liberación dusseliana y marxismo}

La relación entre la producción filosófica de Enrique Dussel y la obra de Karl Marx y el marxismo, es problemática y compleja, puesto que osciló entre posiciones iniciales abiertamente anti-marxistas ${ }^{4}$, hasta que a partir de finales de la década de los setenta, comienza a aproximarse con rigurosidad no dogmática a la obra del filósofo alemán, lo que lo llevó a reconocerse incluso en cercanía con ciertas corrientes del marxismo latinoamericano ${ }^{5}$. Luego de la lectura completa y sistemática de la obra de Marx, el filósofo argentino-mexicano reforzará los planteamientos de la filosofía de la liberación en términos de materialidad y radicalidad política. A partir de dicho proceso, en su

3 Franco, Carlos Del marxismo eurocéntrico al marxismo latinoamericano. Centro de Estudios para el Desarrollo y la Participación, Perú, 1981; Aricó, José. “Marxismo Latinoamericano”, Norberto Bobbio, Nicola Matuceli y Gianfranco Pasquino (eds.), Diccionario de política. Volumen II. Siglo XXI Editores, México,1993, Pp. 942 - 957; Amadeo, Javier. "Mapeando el marxismo", Atilio Borón, Javier Amadeo, Sabrina Gonzalez (comps.). La teoría marxista hoy. Problemas y perspectivas. CLACSO, Argentina, 2006, Pp. 53 - 101; Massardo, Jaime, "La recepción del pensamiento de Karl Marx en América Latina", Revista Estudios N 95, Vol. VIII. Universidad de Valparaíso, 2009, pp. 35-63; Massardo, Jaime, “El lugar del pensamiento de José Carlos Mariátegui en la exploración crítica de las formaciones sociales de América Latina", Documentos de Trabajo, magíster en historia, Universidad de Valparaíso, 2011; Cortés, Martín, Un nuevo marxismo para América Latina. José Aricó: traductor, editor, intelectual. Siglo XXI Editores, Argentina, 2015.

4 La valoración del marxismo al interior de la Filosofía de la Liberación era un evidente punto de fractura. Para Enrique Dussel hasta su exilio en México, el marxismo se concebía como incompatible ontológicamente con la tradición latinoamericana (se le acusó de eurocéntrico) y con la metafísica de la alteridad, su anti-marxismo era propio del catolicismo conservador y tradicionalista de Argentina. Por lo mismo es importante explicitar que Dussel jamás fue marxista de formación o devoción, sino que llegó a Marx desde su condición de exiliado en México y desde su preocupación por la Ética.

5 De hecho, en la obra "El marxismo en América Latina. Antología, desde 1909 hasta nuestros días" de Michael Löwy, el autor se refiere a Dussel como un filósofo y teólogo de la liberación. 
producción filosófica se incorporarán conceptos de evidente raigambre marxista como los de alienación, extrañamiento, exclusión, explotación, trabajo vivo, entre otros ${ }^{6}$.

En 1976 Enrique Dussel, luego de sufrir un atentado de bomba en su domicilio en la ciudad de Mendoza, llega en condición de exiliado a México, país donde publicará el libro "Filosofía de la Liberación"7, obra que sintetiza la trilogía antropológica escrita entre 1961 y 1968 y los tres tomos de "Para una ética de la liberación latinoamericana" publicados entre 1970 y 1974. A partir de ese momento, Dussel comenzará a introducirse en los escritos de Karl Marx elaborados entre 1857 y 1882. Para desarrollar dicho trabajo, analizó la edición castellana editada por Siglo XXI Editores; las ediciones alemanas del MEGA (Marx - Engels - Gesamtausgabe), elaboradas por el Marx-Engels-Lenin Institut de Moscú, y el MEW (Marx - Engels - Werke), publicado en la República Democrática Alemana; además de algunos manuscritos inéditos facilitados por el Internacionaal Instituut voor Sociale Geschiedenis (IISG) de Amsterdam.

Según el propio Enrique Dussel, las inquietudes que lo aproximaron a la obra de Marx fueron la creciente miseria y pobreza del continente americano; la necesidad de efectuar una crítica radical al capitalismo como sistema responsable de la marginalidad y la exclusión; el interés por dotar a la Filosofía de la Liberación de una filosofía económica y política; y la urgencia de superar el dogmatismo marxista-leninista, afianzando la izquierda latinoamericana8.

La lectura dusseliana de la obra de Marx, se caracteriza por considerar severamente el desarrollo histórico de su producción teórica, recogiendo sus idas y venidas, considerando los niveles de "desorden" de su construcción discursiva, deteniéndose en su rigor metódico, analizando la evolución terminológica y conceptual, y estudiando las mutaciones que fue viviendo el plan de trabajo y sus temas de investigación. Además, la lectura dusseliana de Marx recogió las potencialidades teóricas que, desde Latinoamericana, entregaban aportes creativos a la comprensión y transformación de la realidad social. Desde nuestra perspectiva, es una lectura que articula rigurosidad metódica y creatividad interpretativa9.

\footnotetext{
6 Infranca, Antonino, El Otro Occidente. Editorial Antídoto, Argentina, 2000; Fornet-Betancourt, Raúl, Transformación del marxismo. Ediciones Plaza y Valdés, México 2001; Cerutti, Horacio, Filosofía de la Liberación Latinoamericana. Fondo de Cultura Económica. México, 2006.

7 Dussel, Enrique, Filosofia de la Liberación, Nueva América, Colombia, 1996.

8 Dussel, Enrique, "Auto-percepción intelectual de un proceso histórico", Revista Anthropos. No180, España, 1999, pp. 13-36.

9 Para ejemplificar el carácter creativo y heterodoxo de Dussel, es interesante agregar que el filósofo argetinomexicano debatió con aquella tradición del marxismo occidental, representada en Georg Lukacs, Karel Kosik y Ernest Bloch, que desarrollaron el concepto de totalidad para comprender la complejidad de la realidad social. Dussel reconoció la importancia del concepto de totalidad, para analizar el capital ya-dado, pero agregará la importancia del concepto de exterioridad (trabajo vivo) para comprender la realidad más allá del capital. Para Dussel, una vez que el capital existe el concepto de totalidad es fundamental, pero en el proceso de constitución, en el tránsito del dinero al capital, el concepto de exterioridad es clave. Se afirma entonces, que el trabajo vivo (exterioridad, no-capital) es anterior al capital. Lo anterior, le permitió correrse de concepciones economicistas del marxismo que se ocupaban principalmente de medir y cuantificar el problema del valor.
} 
Para Enrique Dussel, el fundamento práctico, histórico y político del pensamiento de Marx, radica en concientizar a los trabajadores de la mistificación, fetichización e injusticias del capital. En palabras de Dussel: "Marx, solidario con los intereses del proletariado, puede ejercer el juicio crítico, ético-práctico, teórico-científico y dar, al mismo tiempo, una conciencia político-revolucionaria al proletariado"10. Desde esta perspectiva Dussel reconoce en Marx un intelectual orgánico, que desarrolla toda su producción teórica, articulada a los intereses y necesidades de la clase obrera, a los sectores explotados y dominados de su tiempo. Su producción teórica se debió y se entregó a los procesos de lucha y liberación de las clases oprimidas. Su servicio como intelectual orgánico, como intelectual y militante radicó en concientizar a los trabajadores de las razones de su miseria, del robo que realiza el capital al trabajo vivo, y por lo mismo, de la urgencia de reapropiarse de su trabajo y sus vidas ${ }^{11}$.

Para el filósofo argentino mexicano, la pertinencia, necesidad y urgencia de Marx para la actualidad Latinoamericana, persiste en tanto su obra permite profundizar en el cuestionamiento ético-político al capitalismo. La subsunción del trabajo vivo al capital, la negación de su alteridad, la cosificación, objetualización y mercantilización del trabajo, representan en su conjunto "el mal originario, la perversidad ética por excelencia de la realidad capitalista" 12 .

Considerando lo anterior, en el siguiente apartado nos detendremos en analizar la categoría de trabajo vivo en la obra de Enrique Dussel, desarrollada particularmente entre los años 1977 y 1990. Para ello, los textos analizados fueron los cuatro libros titulados: "La producción teórica de Marx. Un comentario a los Grundrisse", "Hacia un Marx desconocido. Comentarios a los escritos del 61-63", “El último Marx (1863-1882) y la liberación latinoamericana", y "Las metáforas teológicas de Marx". Y entre los artículos debemos destacar "Sobre la juventud de Marx (1835-1844)"; “El fetichismo en los estudios de juventud de Marx"; "La religión en el joven Marx (1835-1849)". Estos artículos fueron revisados por Dussel, E. (1982), "Praxis Latinoamericana y Filosofía de la Liberación". Por otro lado, "Semejanzas de la estructura de la lógica de Hegel y El Capital de Marx"; "Trabajo vivo y Filosofía de la Liberación"; "Las cuatro redacciones de El Capital", se encuentran en Dussel, E. (1994), "Historia de la Filosofía y Filosofía de la Liberación". Finalmente revisamos el estudio preliminar elaborado por Dussel al "Cuaderno tecnológico-histórico (1851) de Marx".

\footnotetext{
10 Dussel, Enrique, Hacia un Marx desconocido. Un comentario a los Manuscritos del 61-63. México, Siglo XXI Editores, 1988, p. 307.

11Dussel, Enrique, “El programa científico de investigación de Carlos Marx (Ciencia social funcional y crítica), VVAA, Cuadernos de Herramienta. Debate: Marxismo y epistemología. Editorial Herramienta, Buenos Aires, 2007, disponible en: https:/ / www.herramienta.com.ar/articulo.php?id=180

12 Dussel, Enrique, La producción teórica de Marx. Un comentario a los Grundrisse. México, Siglo XXI Editores, 2010 , p. 354.
} 


\section{El trabajo vivo como exterioridad del capital}

Para el filósofo argentino-mexicano el concepto ${ }^{13}$ de trabajo vivo, es central en la obra de Marx, pues es el punto de partida, el desde-donde emerge su discurso crítico. Según los planteamientos dusselianos, el concepto de trabajo vivo, si bien se trabajó con rigurosidad en los Grundrisse, es un concepto que se encuentra implícito en toda la obra del filósofo alemán y es desde él que brotan todos los demás conceptos y categorías. Desde el trabajo vivo, Marx podrá juzgar ética y políticamente las relaciones sociales de dominación propias del capitalismo. En sus palabras: "la categoría de trabajo vivo es el punto de partida meta-físico radical de todo el pensamiento de Marx"14.

Para Dussel, el concepto de trabajo vivo elaborado por Karl Marx, es coincidente con el concepto de exterioridad y alteridad desarrollado por la filosofía de la liberación desde la década de los sesenta15. En coherencia, el trabajo vivo refiere a aquello que se encuentra más allá del horizonte del capital, es su exterioridad, es el no-capital, la subjetividad creadora de valor, es el hontanar exterior al fundamento de la totalidad del capital. El trabajo vivo, productivo, no subsumido al capital es afirmado como exterioridad, como actividad, como posibilidad. El trabajo vivo no-es valor, no-es dinero, no-es capital. El trabajo vivo es lo otro del capital ${ }^{16}$.

Retomando las palabras de Dussel:

El trabajo vivo, en cuanto trabajo humano, actualidad de la persona y manifestación de su dignidad, se sitúa en cuanto tal fuera, más allá, trascendiendo o como lo hemos llamado en otras obras, en la exterioridad del capital. El trabajo vivo no-es el trabajo objetivado. El primero es el hombre mismo, la actividad, la subjetividad, la fuente creadora de todo valor; lo segundo es la cosa, el producto, el valor producido. De esta manera, la crítica del capital (como totalidad cósica) se efectuará desde la exterioridad del trabajo vivo. Exterioridad real más allá, trascendental, del ser del capital, del valor (como cosa efectuada). La realidad del no-capital (...) es el ámbito desde donde se cumple la crítica de la totalidad del valor que se valoriza (cosa): La crítica del capital ${ }^{17}$.

\footnotetext{
13 Según Dussel, para el método elaborado por Marx, un concepto es algo más acabado y verdadero que una categoría. Las categorías son momentos analíticos del concepto, son instrumentos de interpretación. Ahora bien, tanto los conceptos como las categorías, son parte del discurso sistemático y científico de Marx.

14 Ibid, p. 75.

15 La influencia de E. Levinas, es evidente en la interpretación dusseliana sobre el concepto de trabajo vivo en la obra de Karl Marx. Ver: Ortega Reyna, J. Leer el capital, teorizar la política. Contrapunteo de la obra de Enrique Dussel y Bolivar Echeverría en tres momentos, México, UNAM, 2018.

16 El único autor de la bibliografía revisada que polemiza con Dussel en torno a la importancia del concepto de trabajo vivo es Ariel Petruccelli, quien afirmándose en la crítica de Marx al Programa del Gotha elaborado por el Partido Obrero Alemán, sostiene que el trabajo no es la fuente de toda riqueza, puesto que la naturaleza posee la misma importancia que el trabajo.

17 Dussel, E., op., cit., 1988, p. 293.
} 
A lo planteado, se puede agregar que el concepto de trabajo vivo comienza a desarrollarse con profundidad en los Manuscritos de 1861- 1863, pues al decir de Dussel:

(...) hasta ahora, Marx había hablado de trabajo concreto, o abstracto objetivado. Apenas aquí comienza a construir una categoría nueva: 'Trabajo vivo'. La mercancía, el dinero, y así el capital, son valor, trabajo objetivado. Mientras que el trabajo vivo no es valor, sino que es creador de valor. "Ser" valor, "poner" valor y "crear" valor son tres conceptos absolutamente diversos para Marx ${ }^{18}$.

Retomando los textos de Marx, se cita:

Lo único que se contrapone ante el trabajo objetivado es el trabajo noobjetivado, el trabajo vivo. Uno está en el espacio, el otro es trabajo dado en el tiempo; uno está en el pasado, el otro en el presente; uno es valor de uso incorporado, el otro se da como actividad humana en proceso y es comprendido en el proceso de estar objetivándose; uno es valor, el otro es creador de valor. Se intercambiará valor dado por la actividad creadora de valor ${ }^{19}$.

Como ya lo planteamos, el trabajo vivo es una preocupación ética y política en Marx, por ende, la subsunción del mismo por parte del capital, representa la perversidad del sistema capitalista. Cuando el trabajo es incorporado al capital mediante el acto de la subsunción (concepto en el cual nos detendremos más adelante), este pasa a ser una determinación, un momento del capital, perdiendo todo atisbo de autonomía. De esta manera, "El capital se las arregla para que el trabajo vivo produzca la riqueza ajena y la pobreza propia" 20. El capital domina y se apropia del trabajo vivo, es decir de la fuente creadora de todo valor, logrando así asegurar su riqueza imperecedera.

\section{Citando el capítulo № 6 inédito de El Capital, Dussel transcribe:}

Las funciones que ejerce el capitalista no son otras que las funciones del capital mismo - del valor que se realiza succionando trabajo vivo ejercidas con conciencia y voluntad. El capitalista sólo funciona en cuanto capital personificado, es el capital en cuanto persona; del mismo modo el obrero funciona únicamente como trabajo personificado que a él le pertenece como suplicio, como esfuerzo, pero que pertenece al capitalista como sustancia creadora y acrecentadora de riqueza. Ese trabajo, en cuanto tal, se presenta de hecho como un elemento incorporado al capital en el proceso de producción, como factor vivo, variable. La dominación del capitalista sobre el obrero es por consiguiente la de la cosa sobre el hombre, la del trabajo muerto sobre el trabajo vivo ${ }^{21}$

18 Ibid., p. 63.

${ }^{19}$ Idem.

${ }^{20}$ Dussel, E., op., cit., 2010, p. 218.

${ }^{21}$ Dussel, Enrique, El último Marx (1863 - 1882) y la Liberación Latinoamericana. México Siglo XXI Editores, 1990, p. 33. 
La subsunción del trabajo vivo por parte del capital se asemeja a una lucha entre la vida (trabajo vivo) y la muerte (trabajo objetivado). Retomando una metáfora de Marx, Dussel afirma que el capital es una suerte de vampiro, es decir un sujeto muerto, que sólo se vivifica chupando o consumiendo trabajo vivo. Cuando el trabajo vivo es subsumido por el capital, surge la fuerza de trabajo, el trabajo objetivado, asalariado, devenido valor, mercancía, dinero. La subsunción del trabajo vivo, representa la negación y el aniquilamiento de la exterioridad por parte del capital.

A lo anterior, Dussel agregó que existirían tres formas de exterioridad del trabajo vivo: en un sentido histórico, en el cual la propiedad y la vida comunitaria, habrían existido como anterioridad al sistema capitalista; en un sentido abstracto esencial, es decir, como fuente creadora de todo valor; y en un sentido de pobreza, que remite a una condición de exclusión, de desempleo, a la expulsión del proceso de valorización. Ahora bien, y tal como se desprende de este apartado, el filósofo argentino-mexicano, enfatizó en analizar la segunda forma del trabajo vivo, como fuente creadora de todo valor ${ }^{22}$.

Siguiendo a Ortega Reyna (2018), podemos sostener que el trabajo vivo es principio y fundamento de las formas de vida comunitarias, pero "la comunidad no como ideal del pasado, no como remembranza de la sociedad estancada y petrificada; sino comunidad como el control de la producción y el desarrollo de la individualidad sobre la premisa de producción y reproducción de la vida, no de la objetividad espectral del valor" 23 . Retomaremos esto con posterioridad.

Como se puede observar, la relevancia del concepto de trabajo vivo según la lectura dusseliana de la obra de Marx, permite profundizar en el problema de la exterioridad del capital. El trabajo vivo, como fuente creadora de capital, como otro-que-el-capital, contiene un potencial radical para pensar en la superación de la totalidad capitalista. En este sentido, el trabajo vivo, permite pensar en las posibilidades de ruptura y apertura de la totalidad hegemónica. Ahora bien, ¿Cómo se articula este concepto con las categorías que encarnan las luchas contra el capital? ¿Cómo se vincula el trabajo vivo con las categorías de comunidad y movimientos sociales? Parte de esas reflexiones se pueden encontrar en el tratamiento conceptual que realiza Álvaro García Linera en tanto este sería la potencialidad emancipatoria que tendrían los sectores históricamente oprimidos en Bolivia. Más adelante retomaremos este planteamiento.

\section{El aniquilamiento del trabajo vivo: subsunción y plusvalor}

A partir de la lectura de Marx, Enrique Dussel entiende el capital como una relación social de producción, no neutral, sino coactiva y de dominación, basada en la mercantilización y

\footnotetext{
22 Dussel, Enrique, La producción teórica de Marx. Un comentario a los Grundrisse. México, Siglo XXI Editores, 2010.

23 Ortega Reyna, J. Leer el capital, teorizar la política. Contrapunteo de la obra de Enrique Dussel y Bolívar Echeverría en tres momentos, México, UNAM, 2018. P. 70
} 
cosificación del trabajo. El capital es analizado como proceso, como relación, como movimiento. "En realidad el capital no es un instrumento, un ente, una cosa, sino que es un proceso, una totalidad que permanece en el tiempo: fruto del trabajo, instrumento del trabajo, totalidad que incluye al trabajo y al producto del trabajo; un círculo que se retuerce sobre sí mismo, en cuyos diversos momentos siempre es capital" 24 .

Entendido el capital como relación social, el filósofo argentino-mexicano agrega que éste posee la enorme capacidad de producir y reproducirse como relación social de dominación, destruyendo en el trabajador toda otra posibilidad de reproducción de su vida, y ampliando la relación de dominación, al incrementar las condiciones de explotación y aumentar constantemente la masa de trabajadores. Relevante es entonces detenernos en las reflexiones de Dussel sobre la compleja relación entre capital y trabajo (vivo).

Planteado grosso modo, la relación capital/trabajo se explica de la siguiente manera: El/la trabajador/a desprovisto de los medios de producción y urgido por garantizar la reproducción de su vida, debe vender parte de su capacidad de trabajo (mercancía) a cambio del pago de un salario (dinero); con ese dinero puede acceder a la compra de mercancías que le permitirán reproducir su existencia. Por su parte el/la capitalista, recibe fuerza productiva que crea valor, a cambio del pago de un salario (dinero). El/la capitalista, utiliza el trabajo del otro (mercantilización del trabajo) para producir mercancías, las cuales venderá por más dinero. Así, el valor del capital inicial se mantiene, produce y reproduce.

De acuerdo a lo planteado, la relación capital/trabajo se desarrolla a partir de dos términos: Por un lado, el capital posee trabajo objetivado como dinero; y por otro, el trabajo (empobrecido) tiene la necesidad de venderse a sí mismo. Es decir, el capitalista recibe la fuerza productiva del trabajador, la que le permite mantener, producir y reproducir el capital. Y por su parte, el trabajador vende su corporalidad viviente, vende un tiempo determinado de su capacidad de trabajo a cambio de un salario. La compraventa de la fuerza de trabajo se materializa en el contrato o título de propiedad sobre la mercancía, dándose así la subsunción del trabajo al capital.

Mediante la subsunción del trabajo al capital, el trabajo pasa a ser trabajo como capital, es decir, momento constitutivo del capital. "El trabajo produce el capital (que no es sino trabajo objetivado), pero desde el intercambio por contrato de trabajo asalariado el ser del trabajador 'presupone' ahora al capital, es un momento del mismo capital" 25.

Dussel, recogiendo los planteamientos de Marx y a partir de los conceptos de subsunción y plusvalor, acusa la perversidad ética de la relación capital/trabajo. Se afirma así que:

\footnotetext{
24 Dussel, E., op., cit., 2010, p. 132-133.

25 Ibid., p. 146-147.
} 
(...) el momento central ético-político, ontológico y aún meta-físico del pensamiento dialéctico de Marx, se encuentra en el enfrentamiento entre trabajo vivo (en la exterioridad, en la pobreza, como pobre y pueblo) y el poseedor del dinero. La transformación del dinero en capital se debe, exactamente, a la subsunción del trabajo vivo, a su alienación determinada por una relación que es la que transustancia el dinero en capital $^{26}$.

\section{a. Subsunción del trabajo vivo al capital}

La subsunción del trabajo vivo al capital, implica transformar al trabajador en una cosa, en un momento del capital. Marx distinguió en los Manuscritos de 1861 - 1863 tres modos de subsunción del trabajo al capital: En primer lugar, Marx analizó críticamente el fenómeno de la cooperación en el trabajo capitalista. La cooperación, entendida como forma de sociabilidad bajo control del capital, permite aumentar la potencia productiva del trabajo y de esta manera incrementar el plusvalor. En un segundo modo de subsunción, cobra importancia el tema de la división social del trabajo, el cual implica segmentar y tecnificar el proceso productivo a tal punto, que el trabajador pierde el control de lo que produce, siendo únicamente el capital quien controla la totalidad del proceso. Obviamente, la división social del trabajo permite aumentar la potencia productiva e incrementar el plusvalor. Finalmente, un tercer modo de subsunción se logra mediante la incorporación de la maquinaria al proceso productivo. La máquina en tanto capital, logra reducir el valor de las mercancías, pues disminuye el tiempo de trabajo necesario, reduce costos, acelera el proceso productivo, incrementa la intensidad del trabajo, y así logra aumentar el plustrabajo y el plusvalor ${ }^{27}$.

Reconociendo la exterioridad del trabajo vivo con respecto al capital, Dussel, afirma que éste último se las arregla para subsumirlo, incluirlo, incorporarlo como momento de su propia esencia, logrando así concebir al trabajo como un presupuesto del capital. El proceso de subsunción del trabajo vivo, es explicado por el filósofo argentino-mexicano a partir de 2 partes:

1. La subsunción formal. Ésta consiste en la coacción o disolución violenta de los vínculos del hombre y la mujer con la tierra, los instrumentos de trabajo y la comunidad, lo que los obliga a vender su capacidad de trabajo para poder sobrevivir. Al venderse como mercancía, el ser humano deja de ser exterior al capital, subsumiéndose a él. Con la subsunción del trabajo al capital, comienza la negación de la alteridad del trabajo, constituyéndose como ser-para-otro.

\footnotetext{
${ }^{26}$ Dussel, E., op., cit., 1990, p. 214.

27 Dussel, Enrique, Estudio preliminar al "Cuaderno tecnológico-histórico". En Marx, K. (1984). Cuaderno tecnológico-histórico (Extractos de la lectura B 56, Londres 1851). Puebla, México. Editorial Universidad Autónoma de Puebla, 1984.
} 
2. La subsunción material o real. Sólo con la revolución industrial el trabajador será realmente subsumido al capital. Con la introducción de la maquina al proceso de producción, el trabajador deja de ser consciente y rector del proceso productivo. El trabajador y la máquina, al ser subsumidos por el capital, son los momentos productivos por excelencia, son aquellos que crean plusvalor al capital ${ }^{28}$.

Como se puede observar y como ya sostuvimos, es en el proceso de subsunción del trabajo al capital, en la negación de la exterioridad del capital, donde reside la perversidad ética del capitalismo. Enrique Dussel describe ese proceso de la siguiente manera:

La capacidad de trabajo es, en el cara-a-cara anterior al intercambio, la posibilidad de efectivizar su valor de uso (el trabajo mismo). Después de realizado el contrato, el poseedor del dinero promete pagar en el futuro (...) por usar la efectivización o actualización de dicha capacidad (...). El trabajador acepta la oferta y entrega (...): aliena, vende dicha capacidad (...). Jurídica, formalmente, esa capacidad es ahora del propietario del dinero, es capital porque ha subsumido, asimilado, incorporado, totalizado trabajo vivo 29 .

\section{b. El plusvalor como fundamento del capital}

Para Enrique Dussel ${ }^{30}$, el tema del plusvalor ha sido uno de los principales aportes de Marx al desarrollo del pensamiento de la humanidad. Para llegar a constituir la complejidad del concepto de plusvalor, Marx debió abordar categorías más simples como las de dinero, mercancía, trabajo, salario, plustiempo, entre otros; además de desplegar un rico y enorme debate con diferentes representantes de la economía política clásica.

Para Marx, el plusvalor surge como resultado de la explotación del capital sobre el trabajo, y se entiende como aquel proceso mediante el cual el trabajo permite auto-reproducir al capital, mediante su valorización. El plusvalor que posee el capital al término del proceso de producción capitalista, significa que el tiempo de trabajo objetivado en el producto, es mayor que el salario entregado por el capital. En otros términos, el capital no paga al trabajador la totalidad de su trabajo objetivado. Aquello que para el capital es plusvalor, para el obrero es plustrabajo. El obrero realiza un trabajo necesario que permite reproducir su existencia, y un trabajo forzado que permite al capital incrementar su valor. La riqueza del capital proviene del trabajo forzado realizado por el trabajador, del plustrabajo que el obrero entrega al capital. "El capital encubre al obrero su propia autogestación, produce plustrabajo en un intercambio desigual como si fuera igual; el plustrabajo al ser objetivado es el plusvalor. Subjetivamente, en el trabajador, el plustrabajo es el creador del plusvalor, como momento objetivo del capital como capital" 31 .

\footnotetext{
28 Dussel, E., op., cit., 2010.

${ }^{29}$ Dussel, E., op., cit., 1988, p. 69.

30 Idem.

31 Dussel, E., op., cit., 2010, p. 166.
} 
Según nuestro autor, recién en la redacción de El Capital, Marx profundizó en el concepto de plusvalor, elaborando los conceptos de plusvalor relativo y absoluto. El plusvalor relativo, planteado de manera general, pasaría desapercibido al trabajador, en tanto se configura como capital pasando por ejemplo por ser una nueva máquina. Mientras que el plusvalor absoluto, es reconocido como dominación pura y simple, en tanto implica aumentar el tiempo de trabajo o disminuir los salarios. Citando un apartado de Marx en El Capital, Dussel trascribe: "Denomino plusvalor absoluto al producido mediante la prolongación de la jornada de trabajo; por el contrario, al que surge de la reducción (absoluta) del tiempo de trabajo necesario y del consiguiente cambio en la proporción de magnitud que media entre ambas partes componentes de la jornada de trabajo, lo denomino plusvalor relativo" 32 .

El capital, en su dinámica de auto-valorización, oscila entre el plustrabajo absoluto y relativo. Sin embargo, el plustrabajo absoluto tiene un límite: si el trabajador trabaja más de 16 horas diarias, probablemente se enferme o incluso muera, por lo que resulta deseable al capital, incrementar las fuerzas productivas, mediante el desarrollo técnico y tecnológico (plustrabajo relativo). El plusvalor absoluto llega a su límite cuando la explotación pone en riesgo la vida del trabajador; mientras que el plusvalor relativo tiene su límite, cuando la disminución del valor del producto (desvalorización) lo lleva a la crisis.

Finalmente, cabe agregar que, según los planteamientos dusselianos, Marx estableció una clara diferenciación entre los conceptos de ganancia y plusvalor. El concepto de plusvalor es el fundamento de la ganancia y no se da en la esfera de la circulación (como si lo hace la ganancia) sino que en la producción. La ganancia es sólo una forma fenoménica del plusvalor. El plusvalor es lo invisible y esencial, mientras que la ganancia se encuentra en la superficie de los fenómenos. El capital aparenta ser auto-creador de ganancia (e interés), pero esto es simplemente plusvalor, es decir trabajo vivo impago. Así planteado, el filósofo alemán, habría avanzado en desfetichizar y desenmascarar al capital, al descubrir la categoría económica, antropológica y ética de plusvalor.

Considerando los elementos planteados, parece relevante que los movimientos sociales y populares no abandonen las reflexiones sobre las complejas relaciones que asumen el capital y el trabajo, dentro de las cuales los conceptos de trabajo vivo, subsunción y plusvalor son centrales. Esto implica que las formas de subjetivación política de los/as oprimidos/as, explotados/as y excluidos/as asuman como propias las capacidades creativas que se entretejen en los intersticios de las relaciones capitalistas de producción que, si bien son hegemónicas, no alcanzan a cubrir la totalidad de las relaciones sociales. Como veremos a continuación, la categoría de comunidad, desarrollada por Álvaro García Linera, entendida no como antecedente histórico a la valorización del valor sino contemporáneo a este, nos permitirá introducir nuevas claves de lectura que mixturan reflexiones filosóficas y sociológicas sobre la posibilidad real de antagonismo que pueden ejercer ciertos sectores en las luchas radicales por la transformación del estado de cosas.

32 Dussel, E., op., cit., 1990, p. 152. 


\section{Trabajo vivo y comunidad: teoría y práctica en Álvaro García Linera}

Los estudios sobre la producción teórica de García Linera se han centrado, principalmente, en dos elementos: el primero es en el Estado ${ }^{33}$, mientras que el segundo se enfoca en su atípica trayectoria de vida ${ }^{34}$. Otros, como la comunidad y el trabajo vivo ha pasado casi desapercibidos como eje explicativo de su producción. Salvo por Sylvia de Alarcón ${ }^{35}$ y Dominque Temple ${ }^{36}$ no existe reflexión profunda sobre este concepto el cual consideramos central en su configuración teórica.

Ahora bien, estudiar la obra de cualquier intelectual requiere de cierta historicidad, que permitan atender los contextos de producción que contextualizan sus reflexiones. En otras palabras, los conceptos mutan desde situaciones políticas y sociales determinadas, sobre todo en quienes mediante sus libros intervienen en la realidad.

Este breve excursus nos permite situar las reflexiones sobre el trabajo vivo de García Linera y es que alguien con tan atípica trayectoria de vida, que va desde la militancia guerrillera hasta la vicepresidencia, necesariamente debe ser pensado en perspectiva. El apartado que presentamos piensa su desarrollo en tres momentos: su militancia guerrillera, su análisis carcelario, y, finalmente su período de "intérprete". En este último, el intelectual boliviano trata de vincular trabajo vivo con comunidad y estos con los movimientos sociales. Tanto Blanco $^{37}$ como Pulleiro ${ }^{38}$ y Stefanoni ${ }^{39}$ realizan una historización de la producción teórica del autor dejando entrever la multiplicidad de pensamientos que se encuentran presentes en su configuración teórica.

\footnotetext{
33 Scicerone, D., “Estado, poder y revolución. Traducciones gramscianas y poulantzeanas en Álvaro García Linera”, Chile, Demarcaciones, 2017, 1-15; De la Rocha Rada, P., “Estado y estatalidad en René Zavaleta Mercado y Álvaro García Linera”, Bolivia, Bolivian Studies, 2014, 90-101; Levinson, B., “Expediency of Movimiento al Socialismo: leftist or indigenous politics? Inglaterra, Culture, Theory and critique, 2015, 366380.

34 Danilla, Aguiar, “Do autonomismo ao estatismo” trajetória política e intelectual de Álvaro García Linera”, 2011, en:

https://www.academia.edu/25897932/Do_autonomismo_ao_Estatismo_Trajet\%C3\%B3ria_pol\%C3\%ADtica_ e_intelectual_de_\%C3\%811varo_Garc\%C3\%ADa_Linera; García Linera, Á.; Gutiérrez, R.; Benavente, C.; Patzi, F.; Prada, R.; Suárez, H., Bourdieu leído desde el sur, Bolivia, Plural editores, 2000.

35 De Alarcón, S., "Socialismo comunitario", Bolivian Studies, Bolivia, 8:2, 2010, 1-19

36 Temple, Dominique, "Ideología marxista" y "teoría moderna de la reciprocidad" - crítica de las tesis de Álvaro García Linera, 2010, disponible en:

http://dominique.temple.free.fr/reciprocite.php?page=reciprocidad\&id_rubrique=108

37 Blanco, O., “La teoría y el poder: Álvaro García Linera y la nueva utopía boliviana”, Revista Republicana, 14:3, 2013.

38 Pulleiro, A., “De ideólogo guerrillero a intérprete copiloto del proceso boliviano. Seis momentos cruciales en la trayectoria intelectual de Álvaro García Linera", Revista de la Red Intercátedras de Historia de América Latina Contemporánea-Segunda Época, Argentina, 4, 2016, 7-23

39 Stefanoni, Pablo (Comp). La potencia plebeya, Argentina, CLACSO, 2015a.
} 
Teniendo esto en consideración, sostenemos dos cosas: la primera es que el trabajo vivo no se puede comprender de manera aislada sino como fundamento de la práctica comunitaria, sin embargo, y esto es característico de la obra de García Linera, este tiene diferentes tratamientos a partir de cómo se va desarrollando la coyuntura política boliviana. En este sentido, sostenemos que el trabajo vivo excede las interpretaciones productivas que algunos realizan, por ejemplo, Antunes 40 , y se aproximan, aunque manteniendo sus distancias, a como Enrique Dussel ${ }^{41}$ lo analiza, designándolo como exterioridad del capital.

Los diferentes tratamientos sobre el trabajo vivo los identificamos en aproximaciones que lo consideran desde una perspectiva ligada a la producción propiamente tal, hasta la capacidad que tendrían los movimientos sociales de enfrentar la forma valor.

Así, nos proponemos responder preguntas tales como: ¿Qué papel juega el trabajo vivo en la conceptualización comunitaria de García Linera?, ¿Cuál es el dispositivo teórico que permite pensar el trabajo vivo, la comunidad y los movimientos sociales? ¿Dónde se afinca el origen de las reflexiones sobre el concepto? De esta manera, buscamos contornear dos elementos que permitan dialogar la propuesta dusseliana con la del vicepresidente boliviano a partir de una genealogía del trabajo vivo hasta el vínculo que se entabla entre éste y la capacidad política de la comunidad y de los movimientos sociales.

\section{Genealogías del concepto de trabajo vivo en García Linera}

Las primeras aproximaciones hacia el concepto de trabajo vivo en la obra de Álvaro García Linera se pueden rastrear en las primeras reflexiones de su militancia guerrillera. Es en ese entonces, entre finales de la década del 80' hasta los inicios de los 90', donde el actual vicepresidente de Bolivia comienza a pensar las potencialidades explicativas que el elemento contiene en relación a la capacidad emancipatoria de la comunidad.

Es más, según García Linera, la práctica misma de los seres humanos no podría ser comprendida sino se toma en consideración el trabajo vivo, en sus palabras:

Asumir la realidad y la observación de esa realidad es en todo momento una actividad viva del hombre, parte del continuo laboratorio práctico, es asumir en la Historia el punto de vista de la práctica creadora por encima de sus resultados temporales objetivados, esto es, del trabajo vivo como fundamento de la Historia y su transformación ${ }^{42}$.

Además de vislumbrar las potencialidades emancipatorias del concepto, este engendraría una manera particular de comprender la realidad, la cual sólo sería apreciable a partir de

40 Antunes, Ricardo, Los sentidos del trabajo. Ensayo sobre la afirmación y la negación del trabajo. Buenos Aires: Herramienta-Taller de Estudios Laborales, 2005.

41 Dussel, E., op., cit., 1988.

42 García Linera, Á, De demonios escondidos y momentos de revolución: Marx y la revolución social en las extremidades del cuerpo capitalista, Parte 1, Bolivia, Ofensiva Roja, 1991, p. 41. 
la transformación histórica, es decir, en términos epistemológicos, del movimiento de lo real.

De este modo, para García Linera, la realidad no sería algo dado, sino más bien, un constante cambio a partir de cómo se va transformando la Historia. De esta manera, el autor es capaz de vincular, de manera singular, teórica y práctica, puesto que ambas no se pueden comprender sino es mediante una relación contradictoria como unidad dialéctica. En este sentido, la tensión que se genera entre ambos términos produce elementos particulares capaces de tender hacia formas desenajenantes en términos económicos y políticos.

Esto último es fundamental, puesto que es desde aspecto donde se afincarían las posibilidades de transformar la sociedad, por medio de una materialización concreta del trabajo vivo. En otras palabras, la formulación de que, mediante la actividad práctica, y no meramente contemplativa, se puede logran cambios radicales, nos permite ampliar la idea de que el trabajo vivo es solo parte de la producción, ya que en él se encuentra la capacidad de modificar la historia, por ende, este contiene la potencialidad de (re)producir condiciones de vida no alienadas.

Si bien el tratamiento al trabajo vivo no ha sido considerado como un elemento central en la obra del autor en cuestión, creemos que esto se debe a la poca relación que se ha realizado entre sus escritos tempranos y maduros. Esto porque la idea de comunidad encontraría su base explicativa en dicho elemento, puesto que si la comunidad es comprendida como relaciones sociales no alienadas ${ }^{43}$, esto se debe a la extensión del trabajo vivo, puesto que:

Emprender el conocimiento de la comunidad, más allá de la carga ética en la que se regocija un etnicismo (sic) romanticón, requiere hilar los recorridos densos, vigorosos y extendidos del trabajo-vivo la forma social de comunidad, que conquista trechos de autonomía, que no sucumbe a la fatalidad de la autonomización de su poderío y que verifica en el espacio de la producción de medios materiales de vida la elección del común hacer ${ }^{4}$.

Ahora bien, ¿Cómo surgió el salto explicativo que vinculaba el trabajo vivo al concepto de práctica para luego identificarlo como las "trazas de autonomía" de la comunidad?

La respuesta a esa pregunta es compleja de contestar, ya que el grueso de sus reflexiones en torno al trabajo vivo las realiza en dos momentos muy particulares de su trayectoria intelectual: la guerrilla y la cárcel, de este modo, a pesar de que pudiera pensarse una continuidad explicativa, lo que opera es más bien una aproximación que le otorga una

\footnotetext{
43 García Linera, Á. “El socialismo comunitario”. Revista Análisis, Bolivia, 2010a, 7-18.

${ }^{4}$ García Linera, Á.; Gutiérrez, R.; Iturri, J.; Prada, R.; Spedding, A.; Súarez, H.; Velarde, A., Las armas de la utopía: Marxismo provocaciones heréticas, Bolivia, Punto Cero, 1996, p. 99.
} 
relevancia central al concepto para luego, en prisión, profundizar respecto de las expresividades políticas y sociales del trabajo vivo.

En su libro más conocido, Forma valor y forma comunidad45, observamos una cierta ambigüedad en el tratamiento sobre el trabajo vivo, ya que a momentos es tratado en su acepción ligada a los procesos de consumo productivo de los medios de producción y del objeto de trabajo como señalara Marx ${ }^{46}$; sin embargo, la segunda interpretación de esta ambivalencia, es cuando comienza a extender sus reflexiones para que estas terminen conceptualizándolo como el no-ser del valor ${ }^{47}$.

Según García Linera, la forma general que adopta el valor en las formaciones sociales capitalistas es la mercancía. De este modo, las capacidades creadoras de los seres humanos se encuentran subyugadas a una forma de valorización muy particular, a saber, la valorización del valor. Bajo esta propuesta, el proceso de trabajo posee diferentes momentos en la producción que permiten ir analizando el desarrollo mismo de cómo la fuerza de trabajo es el fundamento de la producción de plusvalor que, en definitiva, posibilita la diferenciación de clases. En este sentido, el intelectual boliviano identifica tres aspectos fundamentales del trabajo en el modo de producción capitalista: (i) el trabajo como acto que modifica al objeto (ii), la supresión de la diferencia entre objeto de trabajo y el propósito del trabajo, es decir, el trabajo-en-acto y (iii) la "transubstanciación" de la valorización de la mercancía, o, en otras palabras, el traspaso del trabajo vivo al objeto:

(...) el trabajo al autorrealizarse en su forma de actividad y al consumir las "características objetivas del objeto" de trabajo, consume a la vez los medios de trabajo que, de simples intenciones transformativas materializadas, pasan ahora a ser realidades vivificadas por el trabajo vivo que los pone en movimiento, y ante el cual existen como "conductores", como "transmisores ${ }^{48}$.

Sin embargo, es mediante la subyugación del trabajo vivo a la forma valor, esta última comprendida como la manifestación política de la valorización del valor, donde la primera puede mostrar su potencialidad subversiva. Esto porque la objetivación de él es una singularidad del capitalismo, que no se ha repetido en otros momentos de la historia, ya que aún en sociedades no-capitalistas antiguas la producción permitía la creación productiva por fuera de la dominación de las clases poseedoras, ya sea mediante tierras comunes, uso compartido del suelo, etc., en consecuencia, la subsunción formal de la capacidad creativa del género humano nos permite asumir que en ese aspecto es donde reside la posibilidad de superación del dominio de clases.

45 García Linera, Á., Forma valor y forma comunidad. Aproximación teórica abstracta a los fundamentos civilizatorios que preceden al ayllu universal, España, Traficantes de sueño, $2015 \mathrm{~b}$.

46 Marx, Karl, El Capital, México, Siglo XXI, 2017.

47 García Linera, Á, op., cit., $2015 b$.

48 Ibíd., p. 118. 
La relación entre trabajo vivo y trabajo objetivado es inversamente proporcional, es decir, mientras el segundo se valoriza el primero se desvaloriza, esto porque la objetivación del trabajo implica, en el modo capitalista de producción, una subyugación de los cuerpos, mentes y capacidad creativa de los trabajadores a las clases dominantes, sin embargo: "Esta relación de coerción del trabajo vivo en el proceso del trabajo inmediato, brutal y opresiva, es sin embargo mediata porque está sustentada en una relación formal de iguales que encubre esta radical expropiación: el intercambio del valor de uso de la capacidad de trabajo por su valor de cambio"49. En otras palabras, la forma valor, es decir, la estructuración política de la preponderancia del valor de cambio por sobre el de uso, se erige en la producción como una relación entre iguales, mediadas por el derecho, para subyugar al trabajo vivo y en consecuencia al valor de uso.

Ahora bien, según el autor la forma valor no habría logrado subsumir todas las relaciones a la producción capitalista, es decir, la completitud de la subsunción formal sería más bien un horizonte concreto más que algo real. De esto se desprende, que aún existan formas comunitarias en Bolivia que coexisten indistintamente de su temporalidad histórica. Esta coexistencia no es pacifica, en tanto la forma capitalista busca constantemente subsumir sus producciones precedentes, razón por la cual el trabajo vivo se torna fundamental:

El trabajo vivo no es valor, pues es justamente el "trabajo-no-objetivado", el no-valor; tampoco posee valor porque no contiene trabajo pasado; la que posee valor es la capacidad de trabajo de la que brota, el trabajo-vivo es "actividad fluida", creadora que en el proceso de valorización existe como "creadora del valor", es decir, lo que es directamente su no-ser, el valor. La capacidad de trabajo corporizado ha devenido entonces en "poder" 50.

El trabajo vivo, al existir como no-ser del capital deviene inmediatamente su antagonista en cuanto este representa lo contrario a la objetivación-valorización que requiere el capital para su reproducción. Ahora bien, sería en las formas comunitarias donde residirían las posibilidades de que el trabajo vivo logre imperar a la objetivación, puesto que:

(...) la aglutinación comunitaria en la forma ancestral o arcaica actúa como fuerza de unificación de las condiciones de trabajo, como finalidad de la producción y como fundamental fuerza productiva social y cuerpo unificatorio del trabajo humano en los procesos de trabajo, también en torno a ella se construye la calidad social específica de las relaciones de control y soberanía del trabajo vivo respecto al objeto, al medio y al producto del trabajo ${ }^{51}$ (García Linera, 2015 [1995]: 286).

En otro sentido, las formas de control del trabajo comunitario permiten potenciar la capacidad productiva del trabajo vivo en tanto este sería la contracara de la valorización

\footnotetext{
49 Ibíd., p. 133.

50 Idem.

51 Ibid., p. 286.
} 
del capital. De este modo, la posibilidad de que en las relaciones comunitarias de producción se afinque una potencialidad autonómica residiría justamente en este aspecto, las formas de no-control de este. Esto último lo grafica García Linera en las siguientes palabras:

(...) la comunidad como forma productiva y reproductiva, no es un desdoblamiento a las reglas capitalistas sino una entidad reproductiva que la antecede y que, a pesar de su contemporánea supeditación formal y real a determinadas reglas de funcionamiento económico capitalista, es directamente una forma reproductiva no capitalista; esto es, no fundamentada material ni simbólica ni en la lógica del valor mercantil autonomizado 52 .

En relación a esto último, si entendemos al capitalismo como valorización del valor que objetiva al trabajo vivo en una búsqueda constante por mercantilizarlo, en este proceso, se estaría refutando a sí mismo, ya que la reproducción del trabajo vivo implicaría, en el caso boliviano, de por sí el trabajo no-alienado como fundamento de las formas comunitarias de producción. En este sentido, la potencialidad antagonista de la comunidad se encuentra en una disputa con la forma valor. En palabras de Marx: "El capital no consiste en que el trabajo acumulado sirva al trabajo vivo como medio para una producción. Consiste en que el trabajo vivo sirva al trabajo acumulado como medio para conservar y aumentar su valor de cambio" 53 . Es decir, las formas de subyugación del trabajo vivo serían un aspecto central para comprender el modo de producción capitalista en condiciones de coexistencia de modos de producción cuyas temporalidades históricas no fueran contemporáneas.

La genealogía del concepto en la obra de Álvaro García Linera se encuentra presente en su producción intelectual desde el comienzo de sus reflexiones donde, además, intenta ponerlas en práctica politicamente. El desarrollo del trabajo vivo le ha permitido comprender el fundamento de la práctica donde se afincarían las potencialidades antagónicas de las fuerzas comunitarias en tanto estas representan formas de control diferentes a las relaciones de producción capitalista. En este sentido, la capacidad creadora del trabajo vivo se encontraría con mayores posibilidades disruptivas a partir de la comunidad. Esto se debe a que: "la comunidad ancestral solo podía desarrollarse y hacer prevalecer sus rasgos colectivas en la medida en que fuera capaz de promover levantamientos generales contra el régimen capitalista" 54 .

52 García Linera, Á, “Comunidad, capital y Explotación: comentarios al libro de Félix Patzi”. Temas Sociales 20:30, 1998, 87-115, p. 87.

53 Marx, K., “Trabajo asalariado y capital”, Karl Marx y Friedrich Engels, Obras Escogidas T. 1, España, AKAL, 2015, p. 86

54 García Linera, Á. Introducción al cuaderno Kovalevsky, La Paz, Ofensiva Roja, 1989, p. 51 


\section{Comunidad, exterioridad y movimientos sociales: la consolidación conceptual y la potencialidad política del trabajo vivo}

Como vimos, trabajo vivo y comunidad se corresponden en la medida en que el segundo es el dispositivo teórico-práctico del primero. El fundamento de las formaciones comunitarias se encontraría en la capacidad de insubordinación de este último como práctica no alienada de producción ${ }^{55}$. Esto se debe a que la comunidad no sería un locus geográfico específico sino más bien una forma no-capitalista de producción, donde propiedad y posesión no se corresponden.

El concepto de trabajo vivo en la obra de García Linera tiene al menos dos elementos que nos permiten aproximarnos a él. Primero como el fundamento de las relaciones comunitarias ${ }^{56}$ y segundo, a partir de su vínculo con la comunidad, como expresión de los movimientos sociales ${ }^{57}$. La manifestación de lo comunitario en el quehacer intelectual del autor se posiciona como un eje central en su construcción teórica que atraviesa los diferentes momentos de su obra 58 .

Si la comunidad es en sí una producción no-capitalista, esta tendría una forma de trabajo específica, el trabajo vivo. En este sentido, la potencialidad subversiva que implica este, se puede caracterizar como una interioridad radical dentro del capitalismo que, como tal, es capaz de abrir un punto de fuga, cuando se encuentra en prácticas comunitarias, del trabajo asalariado y la explotación dado que esta, según García Linera, solo es capaz de generar valores de uso, en su más amplio sentido, es decir, cualidad pura ${ }^{59}$.

El trabajo vivo, entonces, no se encontraría exclusivamente en la producción en sí, sino que es, paralelamente, la capacidad transformadora de los sujetos explotados y excluidos. De este modo, podríamos decir que este adquiere formas particulares de expresividad toda vez que la creatividad logre exceder los márgenes de la subsunción mediante relaciones sociales insubordinadas, formas de organización alternativa, etc.

Una de aquellas sería la comunidad. En esta se podría concretizar el trabajo vivo como fundamento de la transformación histórica, puesto que allí se encontrarían relaciones de producción no alienadas. Estas formas productivas comunitarias se explicarían a partir de la diferencia entre propiedad y posesión, la que permite emerger el enfrentamiento entre formas de trabajo, uno de la modernidad y otro de la comunidad:

\footnotetext{
55 García Linera, Á., op., cit., 1991.

56 García Linera, Á., op., cit., 1989.

57 García Linera, Á., “Sindicato, multitud y comunidad. Movimientos sociales y formas de autonomía política en Bolivia", 2001a, Pablo Stefanoni (Comp). La potencia plebeya, Argentina, CLACSO, 2015a, 347-422.

58 García Linera, Á., op., cit., 1989; García Linera, Á., op., cit., 2001; García Linera, Á., op., cit., 2010.

59 En este aspecto, podemos decir que las interpretaciones realizadas por García Linera, en relación al trabajo vivo, se cruzan con las del marxista italiano, Antonio Negri. Este último considera que es en este concepto donde se expresa una capacidad de insubordinación capaz de subvertir las lógicas del capital en la medida en que la creación de las clases subalternas no sea objetivada (trabajo muerto) ni se valorice (trabajo productivo). Véase: Negri, A \& Hardt, M. El trabajo de Dionisios. Una crítica a la forma-Estado, España, AKAL, 2003
} 
Marx da cuenta de la imposibilidad de aplicar el mismo concepto de "propiedad" usado en Europa, para estudiar sociedades en donde la tierra no puede ser alienada (vendida). Cambiando (...) "propiedad" por "posesión", Marx prefería hablar de la comunidad como "dueña" de las tierras, y de los individuos trabajadores como "poseedores" de ella ${ }^{60}$.

De este modo, la comunidad tendría características particulares sobre las cuales reposaría una visión del trabajo no-capitalista.

Ahora bien, ¿qué es la comunidad para García Linera? Diremos que es una forma de asociatividad sanguínea-cultural que experimenta formas de producción no-capitalistas ${ }^{61}$. De este modo, la comunidad no sería la imagen folclorizada de relaciones que se tiene de ella, como pasado, sino que ésta, se encuentra presente en la actualidad resistiendo al avance de la modernidad capitalista. En este sentido, es que la insubordinación del trabajo vivo cobra relevancia ya que para el Vicepresidente sería en las relaciones comunitarias donde, además de la clase obrera, existiría un potencial emancipatorio que permitiría dar el salto histórico al comunismo.

Esta descripción de la comunidad nos permite adentrarnos en la importancia que tiene esta en la obra de García Linera, pero también la manera en que desde ella se desprende su problematización de los movimientos sociales, puesto que estos serían capaces de propiciar formas de autonomía política ${ }^{62}$, condición necesaria para la insubordinación del trabajo vivo.

Esta característica es descrita a partir de que, en los movimientos sociales, reside la materialización del trabajo vivo. En palabras del autor:

Claro, si el capital, como sociedad de antagonismos, explotación y beneficios privados como las anteriores sociedades escindidas en clases, se levanta, sin embargo, sobre el trabajo social universal, la posibilidad de la emancipación humana como un todo deja de ser una añoranza infundada, para hallar en esa universalidad perversamente trabajada por el capital la condición material de posibilidad de una acción humana conjunta, que ya no devenga propiedad y poderío privado, sino posesión y poderío común universal de los propios productores ${ }^{63}$.

Los movimientos sociales, a su vez, son pensados como un agente capaz de democratizar la política64, en ellos se afinca la capacidad potencial de subvertir las relaciones sociales de

60 García Linera, Á., op., cit., 1989, p. 34

61 García Linera, Á., op., cit., 1998.

62 García Linera, Á., op., cit., 2001.

63 García Linera, Á., "El manifiesto comunista y nuestro tiempo”, 1999c, Pablo Stefanoni (Comp.), La potencia plebeya, Argentina, CLACSO, 2015a, 71-172, p. 78

${ }^{64}$ García Linera, Á., Las tensiones creativas de la revolución: quinta fase del proceso de cambio, Bolivia,

Ediciones de la Vicepresidencia, 2011. 
centralización generadas por la forma-Estado. Su vínculo con el trabajo vivo, estaría ligado a pensarse como la expresividad de este como ajena a la producción capitalista, por cuanto estos producen formas organizativas comunitarias, las que a su vez, dan cuenta de formas no enajenadas de relaciones sociales, es decir, poseen una dimensión performativa65, lo que va determinando que en su interior vayan contorneando materializaciones que se construyen a partir de lo histórico-social.

Lo último se encuentra engarzado con un tipo de movimiento social, la forma multitud. Esta tendría su origen en los cambios introducidos por las modificaciones del patrón de acumulación neoliberal, la desindicalización y disgregación productiva ${ }^{66}$ que sufrió la clase obrera: "Sin embargo, el desmoronamiento de las antiguas estructuras de movilización nacional con efecto estatal ha mostrado una multifacética, compleja y generalizada urdimbre organizativa de la sociedad subalterna, enraizada en ámbitos locales de preocupación" 67 .

En términos analíticos, García Linera propone una aproximación diferenciada a los movimientos sociales: por una parte, una mirada interna (conformación y cultura organizativa) y otra externa, centrada particularmente en las oportunidades políticas y en los nodos de sentido.

Si consideramos que el capital no es sólo una cuestión económica ligada a la producción sino también una forma de producción de subjetividad y organización ${ }^{68}$, podemos pensar que lo no-capital, es decir, aquello que no contribuye a la valorización del valor, es un aspecto que no esté mediado por la forma valor. En este sentido se puede apreciar la definición de trabajo vivo en este período del pensamiento de García Linera, a partir de: "El capital como trabajo objetivado [y] el trabajo vivo, como "trabajo no-objetivado", como lo "único que no es capital" es el punto de decisivo del concepto marxista de revolución y de sujeto revolucionario" 69 .

Si la comunidad es capaz de generar una socialidad no alienada ni mediada por el capital este puede ser considerado como una producción del trabajo vivo. Con esto nos referimos a la organización radicalmente democrática que implica lo comunitario y que no permite la diferenciación entre dominados y dominantes.

Volviendo a la forma multitud como tipo de movimiento social, decimos que en ella existe una influencia en su interior que permite pensar que allí se anida la potencia del trabajo vivo, puesto que:

\footnotetext{
65 García Linera, Á., op., cit., 2001

66 Idem.

67 Ibíd., p., 379.

68 Salomon, J., Valor y comunidad: reencuentro marxista boliviano. Una conversación con Álvaro García Linera, Bolivia, Ediciones de la Vicepresidencia, 2016.

69 García Linera, Á., op., cit., 1999, p. 78.
} 
La democracia comunal fusiona, entonces, la acción comunicativa, mediante la cual los comunarios deliberan sus acuerdos para formar discursivamente un horizonte de acción común, con la acción normativa, que hace que los acuerdos así producidos cuenten con un carácter obligatorio respecto a los sujetos colectivos e individuales partícipes en su elaboración. Esto tiene que ver con la preponderancia de lo común por encima de lo individual en las estructuras sociales tradicionales ${ }^{70}$.

Esta asociatividad ancestral no sólo está presente en la forma comunidad, como movimiento social, sino que es parte de lo que podríamos denominar "bloque plebeyo", es decir, permea al conjunto de sectores subalternos de la abigarrada sociedad boliviana.

Esto último es importante, ya que los movimientos sociales en Bolivia deben ser analizados desde la amplitud del término. Las formas de contestación al neoliberalismo dan cuenta de la característica abigarrada de la sociedad altiplánica, sin ella, probablemente existirían sectores sociales más unificados a partir de una demanda que interpela al Estado y no una polifonía de sujetos capaces de plantearse una estrategia de poder. Pero, justamente en esa pluralidad se pueden apreciar las influencias del trabajo vivo:

La preexistencia de "comunidades solidarias locales" como base de la movilización, y el que la gran fuerza de agregación de los regantes recoja la vigorosa tradición de la cultura y experiencia organizativa del movimiento campesino, formadas entre los años 1930-1960, tiende a reforzar esa mirada. Sin embargo, como ya explicamos en el anterior punto, la forma multitud no solo presenta redes de asociación con base comunal o tradicional; también contiene, y de una manera creciente, grupos de base asociativa y electiva emergentes de los intermitentes y mutilados procesos de modernización social ${ }^{71}$.

Esta extensa cita demuestra dos aspectos importantes, primero que los movimientos sociales emergen a partir de problemas irresueltos y que se vieron incrementados a partir de los intentos privatizadores de los inicios del siglo XXI y también que las formas organizativas, es decir, lo interno de la acción colectiva, contiene culturas organizativas dispares, flexibles y que atienden a características históricas diferenciadas. Las experiencias acumuladas por los sujetos sociales se manifiestan en dichos elementos. El trabajo vivo, como expresión de la comunidad, se puede apreciar en este tipo de experiencia, de forma política democrática, en la performatividad de la organización, en definitiva, en la manera de concebir la capacidad subversiva no sólo emplazando al Estado, sino también como una construcción no-capitalista, como valor de uso.

\footnotetext{
70 García Linera, Á., op., cit., 2001, p. 413.

71 Ibíd., p. 384
} 


\section{Notas finales}

Tal como hemos demostrado, la categoría de trabajo vivo, cuando se analiza más allá de la producción material, ofrece diferentes alternativas interpretativas, algunas de las cuales, han sido trabajadas por Enrique Dussel y Álvaro García Linera. Desde nuestra perspectiva, tanto el concepto de exterioridad dusseliano como la correspondencia con la comunidad en García Linera, dan cuenta de la fertilidad explicativa que posee para comprender la co-existencia de formaciones capitalistas y formas no-capitalistas de producción.

La abigarrada rebeldía contemporánea72 (Pacheco \& Ortega, 2018) daría cuenta de cómo la comunidad ha cobrado centralidad en los procesos políticos contemporáneos, dado que esta sería capaz de ampliar el nodo explicativo central por excelencia del marxismo, es decir, la clase social, hacia formaciones sociales que no necesariamente se pueden identificar con esta. Con esto no afirmamos que exista una jerarquización de relevancia política de una (clase social) por sobre la otra (comunidad), sino más bien una complejidad social imbricada propia de las formaciones sociales donde la lucha de clases pareciera librarse en diferentes temporalidades históricas. De este modo, ambas posibilitan formas de subjetivación antagonista a la producción y re-producción del valor. En otras palabras, con el presente artículo hemos intentado mostrar que la categoría de trabajo vivo aportaría en esclarecer el fundamento que permitiría extender los márgenes analíticos del marxismo hacia otras formas posibles de interpretar la realidad en la medida en que la disputa entre capital y trabajo continúa teniendo una importancia nodal en las luchas por la emancipación. De esto se desprende que otras formas de opresión, no exclusivamente clasistas, adquieran un estatus analítico más complejo de parte del marxismo, ya que en ellas también se encuentra la potencialidad de devenir no-capital, exterioridad, etc., las que en perspectiva interseccional, darían cuenta de formas nuevas (aunque no novedosas) de enfrentamiento entre sectores sociales.

Tanto Dussel como García Linera, importantes pensadores marxistas de nuestros tiempos, analizan el concepto de trabajo vivo y podríamos decir que hay una complementariedad, un diálogo que aún no se ha dado en términos presenciales, pero que da cuenta de las maneras reflexivas sobre las que se interpreta el pensamiento del filósofo alemán. Esta hermenéutica ha permitido, entre otras cosas, utilizar heréticamente las herramientas del análisis marxista para comprender y poner en práctica, de manera heterodoxa, los planteamientos clásicos del marxismo y así, identificar las maneras en las que es posible pensar un camino emancipatorio.

De lo anterior, podemos reconocer que la noción de exterioridad dusseliana, se corresponde con la idea de los movimientos sociales en su dimensión performativa, propuesta por García Linera, ya que, si la comunidad es portadora del trabajo vivo, como capacidad creativa de cualidad ajena a la valorización del valor, esta podría ser analizada

72 Pacheco, V., \& Ortega, J., La abigarrada rebeldía contemporánea: la apuesta por la comunidad, Revista Latinoamericana del Colegio Internacional de Filosofía, Chile, 2018, pp, 33-51. 
en su potencialidad de no-capital. Un segundo elemento, que requiere de mayor profundidad de tratamiento, es la extrapolación que podríamos hacer entre la forma valor, analizada por el vicepresidente, que implica un proceso de subjetivación donde la organización social recibe efectos de división a través de formas como el Estado que separan en partes la totalidad social, podría verse enfrentada con el análisis de la categoría estudiada dado que en la obra del boliviano existiría una correlación positiva entre democratización y comunidad, en consecuencia, las formas de organización radicalmente democráticas implicarían momentos de subjetivación que, influidos por el trabajo vivo, se podrían pensar, potencialmente, como procesos de antagonismo hacia la primacía de la valorización del valor.

Finalmente, nos gustaría señalar las preguntas abiertas que nos surgen luego de realizar este artículo y que demuestran la fecundidad generada en el diálogo entre estos autores. Una de ellas es la potencia analítica que ofrece el trabajo vivo, de este modo ¿qué otras variantes del marxismo latinoamericano retoman algunas dimensiones aquí esbozadas del trabajo vivo para su corpus teórico? Quizás, el concepto de "polo marginal" del sociólogo peruano, Aníbal Quijano, sea uno de los que, de manera creativa, utiliza algunos elementos que sería interesante de considerar para ver su posterior decantamiento en la "colonialidad del poder". Asimismo, el filósofo ecuatoriano-mexicano, Bolívar Echeverría, otorga un lugar importante de sus reflexiones al trabajo vivo, desde una perspectiva analítica diferenciada tanto a la de Enrique Dussel como a la de Álvaro García Linera que sería importante destacar. Por último, nos gustaría señalar que la conceptualización que hemos revisado de los autores no surge como una reflexión escolástica, si no como una forma de repensar los caminos emancipatorios, es decir, no utilizando palabras sagradas ni manuales cerrados, más bien recorriendo analítica y profundamente nuestra realidad.

\section{Bibliografía}

- Acha, Omar \& D'Antonio, Débora “Cartografía y perspectivas del marxismo latinoamericano", Revista Contra Corriente, México, 2010, pp. 210-256.

- Amadeo, Javier. "Mapeando el marxismo", Atilio Borón, Javier Amadeo, Sabrina Gonzalez (comps.). La teoría marxista hoy. Problemas y perspectivas. CLACSO, Argentina, 2006, pp. 53-101.

- Antunes, Ricardo, Los sentidos del trabajo. Ensayo sobre la afirmación y la negación del trabajo. Buenos Aires: Herramienta-Taller de Estudios Laborales, 2005.

- Aricó, José. "Marxismo Latinoamericano", Norberto Bobbio, Nicola Matuceli y Gianfranco Pasquino (eds.), Diccionario de política. Volumen II. Siglo XXI Editores, México,1993, Pp. 942 - 957.

- Blanco, O., “La teoría y el poder: Álvaro García Linera y la nueva utopía boliviana", Revista Republicana, 14:3, 2013.

- Cerutti, Horacio, Filosofía de la Liberación Latinoamericana. Fondo de Cultura Económica. México, 2006. 
- Cortés, Martín, Un nuevo marxismo para América Latina. José Aricó: traductor, editor, intelectual. Siglo XXI Editores, Argentina, 2015.

- De Alarcón, S., "Socialismo comunitario", Bolivian Studies, Bolivia, 8:2, 2010, 1-19.

- De la Rocha Rada, P., “Estado y estatalidad en René Zavaleta Mercado y Álvaro García Linera", Bolivia, Bolivian Studies, 2014, 90-101.

- Dussel, Enrique, "Auto-percepción intelectual de un proceso histórico", Revista Anthropos. №180, España, 1999, pp. 13-36.

- Dussel, Enrique, El último Marx (1863 - 1882) y la Liberación Latinoamericana. México Siglo XXI Editores, 1990.

- Dussel, Enrique, Estudio preliminar al "Cuaderno tecnológico-histórico". En Marx, K. (1984). Cuaderno tecnológico-histórico (Extractos de la lectura B 56, Londres 1851). Puebla, México. Editorial Universidad Autónoma de Puebla, 1984.

- Dussel, Enrique, Filosofia de la Liberación, Nueva América, Colombia, 1996.

- Dussel, Enrique, Hacia un Marx desconocido. Un comentario a los Manuscritos del 61-63. México, Siglo XXI Editores, 1988, p. 307.

- Dussel, Enrique, La producción teórica de Marx. Un comentario a los Grundrisse. México, Siglo XXI Editores, 2010.

- Franco, Carlos Del marxismo eurocéntrico al marxismo latinoamericano. Centro de Estudios para el Desarrollo y la Participación, Perú, 1981.

- García Linera, Á, “Comunidad, capital y Explotación: comentarios al libro de Félix Patzi". Temas Sociales 20:30, 1998, 87-115.

- García Linera, Á, De demonios escondidos y momentos de revolución: Marx y la revolución social en las extremidades del cuerpo capitalista, Parte 1, Bolivia, Ofensiva Roja, 1991.

- García Linera, Á. “El socialismo comunitario". Revista Análisis, Bolivia, 2010a, 718.

- García Linera, Á. Introducción al cuaderno Kovalevsky, La Paz, Ofensiva Roja, 1989.

- García Linera, Á., “El manifiesto comunista y nuestro tiempo", 1999c, Pablo Stefanoni (Comp.), La potencia plebeya, Argentina, CLACSO, 2015a, 71-172.

- García Linera, Á., "Sindicato, multitud y comunidad. Movimientos sociales y formas de autonomía política en Bolivia", 2001a, Pablo Stefanoni (Comp). La potencia plebeya, Argentina, CLACSO, 2015a, 347-422.

- García Linera, Á., Forma valor y forma comunidad. Aproximación teórica abstracta a los fundamentos civilizatorios que preceden al ayllu universal, España, Traficantes de sueño, 2015b.

- García Linera, Á., Las tensiones creativas de la revolución: quinta fase del proceso de cambio, Bolivia, Ediciones de la Vicepresidencia, 2011.

- García Linera, Á.; Gutiérrez, R.; Benavente, C.; Patzi, F.; Prada, R.; Suárez, H., Bourdieu leído desde el sur, Bolivia, Plural editores, 2000.

- García Linera, Á.; Gutiérrez, R.; Iturri, J.; Prada, R.; Spedding, A.; Súarez, H.; Velarde, A., Las armas de la utopía: Marxismo provocaciones heréticas, Bolivia, Punto Cero, 1996. 
- Hobsbawm, Eric, Historia del marxismo. El marxismo en la época de la II Internacional, España, Brugera Vol. 3, 1980b.

- Hobsbawm, Eric, Historia del marxismo. El marxismo en la época de la II Internacional, España, Brugera vol. 4, 1980c.

- Hobsbawm, Eric, Historia del marxismo. El marxismo en la época de la II Internacional, España, Brugera vol. 5, 1981.

- Hobsbawm, Eric, Historia del marxismo. El marxismo en tiempos de Marx, España, Brugera Vol. 2, 1980a.

- Infranca, Antonino, El Otro Occidente. Editorial Antídoto, Argentina, 2000; FornetBetancourt, Raúl, Transformación del marxismo. Ediciones Plaza y Valdés, México 2001.

- Kolakowski, Leszek, Las principales corrientes del marxismo. Tomo II: La edad de oro. Alianza Editorial, Madrid, 1985.

- Levinson, B., “Expediency of Movimiento al Socialismo: leftist or indigenous politics? Inglaterra, Culture, Theory and critique, 2015, 366- 380.

- Marx, K., "Trabajo asalariado y capital”, Karl Marx y Friedrich Engels, Obras Escogidas T. 1, España, AKAL, 2015.

- Marx, Karl, El Capital, México, Siglo XXI, 2017.

- Massardo, Jaime, "El lugar del pensamiento de José Carlos Mariátegui en la exploración crítica de las formaciones sociales de América Latina", Documentos de Trabajo, magíster en historia, Universidad de Valparaíso, 2011.

- Massardo, Jaime, "La recepción del pensamiento de Karl Marx en América Latina”, Revista Estudios N 95, Vol. VIII. Universidad de Valparaíso, 2009, pp. 35-63.

- Negri, A \& Hardt, M. El trabajo de Dionisios. Una crítica a la forma-Estado, España, AKAL, 2003.

- Ortega Reyna, J. Leer el capital, teorizar la política. Contrapunteo de la obra de Enrique Dussel y Bolívar Echeverría en tres momentos, México, UNAM, 2018.

- Pacheco, V., \& Ortega, J., La abigarrada rebeldía contemporánea: la apuesta por la comunidad, Revista Latinoamericana del Colegio Internacional de Filosofía, Chile, 2018, pp, 33-51.

- Pulleiro, A., "De ideólogo guerrillero a intérprete copiloto del proceso boliviano. Seis momentos cruciales en la trayectoria intelectual de Álvaro García Linera", Revista de la Red Intercátedras de Historia de América Latina ContemporáneaSegunda Época, Argentina, 4, 2016, 7-23.

- Salomon, J., Valor y comunidad: reencuentro marxista boliviano. Una conversación con Álvaro García Linera, Bolivia, Ediciones de la Vicepresidencia, 2016.

- Scicerone, D., “Estado, poder y revolución. Traducciones gramscianas y poulantzeanas en Álvaro García Linera”, Chile, Demarcaciones, 2017, 1-15.

- Stefanoni, Pablo (Comp). La potencia plebeya, Argentina, CLACSO, 2015a.

\section{Recursos Web:}

- Dussel, Enrique, “El programa científico de investigación de Carlos Marx (Ciencia social funcional y crítica), VVAA “Cuadernos de Herramienta. Debate: Marxismo y 
epistemología. Editorial Herramienta, Buenos Aires, 2007, disponible en: https:// www.herramienta.com.ar/articulo.php?id=180.

- Danilla, Aguiar, "Do autonomismo ao estatismo" trajetória política e intelectual de Álvaro García Linera”, 2011, en:

https:// www.academia.edu/25897932/Do_autonomismo_ao_Estatismo_Trajet\%C 3\%B3ria_pol\%C3\%ADtica_e_intelectual_de_\%C3\%81lvaro_Garc\%C3\%ADa_Linera

- Temple, Dominique, "Ideología marxista" y "teoría moderna de la reciprocidad" crítica de las tesis de Álvaro García Linera, 2010, disponible en: http:/ / dominique.temple.free.fr/reciprocite.php?page=reciprocidad\&id_rubrique $=108$ 